OPEN ACCESS

Edited by:

Dan Larhammar,

Uppsala University, Sweden

Reviewed by:

Sara V. Good

University of Winnipeg, Canada

Tsuyoshi Kawada,

Suntory Foundation for Life Sciences,

Japan

*Correspondence:

Masatoshi Mita

bio-mita@aoni.waseda.jp

Specialty section:

This article was submitted to

Experimental Endocrinology,

a section of the journal

Frontiers in Endocrinology

Received: 05 December 2018

Accepted: 04 March 2019

Published: 25 March 2019

Citation:

Mita M (2019) Starfish Gonadotropic Hormone: From Gamete-Shedding

Substance to Relaxin-Like

Gonad-Stimulating Peptide.

Front. Endocrinol. 10:182.

doi: 10.3389/fendo.2019.00182

\section{Starfish Gonadotropic Hormone: From Gamete-Shedding Substance to Relaxin-Like Gonad-Stimulating Peptide}

\author{
Masatoshi Mita* \\ Center for Advanced Biomedical Sciences, Research Institute for Science and Engineering, Waseda University, Tokyo, Japan
}

The first report of a gonadotropic substance in an invertebrate hot-water extract of radial nerve cords from starfish Asterias forbesi that induced the shedding of gametes when injected into the coelomic cavity in a ripe individual occurred in 1959. The active substance was named gamete-shedding substance (GSS) or radial nerve factor. GSS is the primary mediator of oocyte maturation and ovulation in starfish. However, the effect of GSS is indirect. Resumption of meiosis in immature oocytes and release from the ovary are induced by a second mediator, maturation-inducing hormone, identified as 1-methyladenine (1-MeAde) in starfish. The role of GSS is to induce 1-MeAde production by ovarian follicle cells. Thus, GSS was redesignated as gonad-stimulating substance (also GSS). Although GSS has been characterized biochemically as a peptide hormone, identification of the chemical structure had to wait until 2009. Fifty years after the initial finding, GSS was purified from the radial nerve cords of starfish Patiria pectinifera (P. pectinifera). The purified hormone was a heterodimer composed of A- and B-chains, with disulfide cross-linkages. Based on its cysteine motif, GSS is classified as a member of the insulin/insulin-like growth factor (IGF)/relaxin superfamily. More specifically, phylogenetic sequence analysis revealed that $P$. pectinifera GSS is a member of the relaxin-type peptide family. Therefore, GSS in starfish has been redesignated as relaxin-like gonad-stimulating peptide (RGP). Subsequently, orthologs of $P$. pectinifera RGP have been identified in other starfish species, including Asterias amurensis (A. amurensis), and Aphelasterias japonica (A. japonica).

Keywords: gonadotropic hormone, gamete-shedding substance, gonad-stimulating substance, relaxin-like gonad-stimulating peptide, 1-Methyladenine, starfish

\section{INTRODUCTION}

Regulation of reproduction differs among animals. This variety can appear more as a gathering of exceptions, and it is hard to explain reproductive regulation by only a single mechanism. In fact, the meiotic stage of oocytes for the timing of fertilization differs widely among animals. Sea urchin eggs have long been used as a principal material for the study of developmental biology, because both eggs and spermatozoa are obtained easily by injecting isotonic potassium chloride into the body cavity. In other words, sea urchin oocytes have already accomplished meiotic maturation within the ovaries during the breeding season long before spawning occurs. On the other hand, in starfish 
belonging to the same phylum as sea urchins, Echinodermata, meiosis is arrested at the prophase of the first meiotic stage in fully grown oocytes just before spawning. These immature oocytes within the ovary still possess a large nucleus (germinal vesicle $[\mathrm{GV}]$ ) and fail to undergo fertilization even though oocytes isolated mechanically from ovaries are inseminated. In order to undergo normal fertilization, the immature oocytes must resume meiotic division just before spawning under the influence of an active substance. Thus, starfish are suitable animals for the study of regulatory mechanism of oocyte maturation and ovulation. It is also important that 1-methyladenine (1-MeAde) has been purified from starfish $A$. amurensis (1), and 1-MeAde on its own is capable of inducing oocyte maturation and ovulation. Therefore, 1-MeAde in starfish is the first maturationinducing hormone $(\mathrm{MIH})$ identified in the animal kingdom. Numerous studies about the hormonal role of 1-MeAde on oocyte maturation in starfish have been published to date (2-9). On the other hand, the chemical structure of the gonadotropic hormone of starfish remained unknown for 50 years, even though its activity had been found 10 years before the discovery of 1MeAde. In 2009, starfish gonadotropic hormone was the first identified among invertebrates (10). In this review, the outcome of research on starfish gonadotropic hormone from its discovery to its identification is described.

\section{GAMETE-SHEDDING SUBSTANCE}

Gonadotropic hormones play important regulatory roles in reproduction in both vertebrates and invertebrates. In vertebrates, two kinds of gonadotropins are secreted from pituitary glands: follicle-stimulating hormone (FSH) and luteinizing hormone (LH). These two glycoproteins are structurally and functionally conserved across various species. Glycoprotein hormones that include FSH, LH, thyroid stimulating-hormone (TSH) and thyrostimulin (TS) are widely distributed not only in vertebrates but also in invertebrates (11). However, it is unclear whether pituitary glycoprotein hormones are involved in reproduction in invertebrates.

In 1959, Chaet and McConnaughy (12) first reported that injecting a hot-water extract of the radial nerve cords of starfish Asterias forbesi induced the release of eggs and spermatozoa from ripe females and males, respectively. This finding opened the door to the study of reproductive endocrinology in asteroids. An active substance present in the radial nerve cords has been found in all starfish species so far tested (about thirty) (3). The extract prepared from male nerve cords can induce the release of gametes in both sexes (13). Not only whole animals (13-15) but also isolated gonads (16-18) respond to the radial nerve factor, so the active substance is considered to act directly on the gonads. Thus, the substance was first designated as gamete-shedding substance (GSS) (18).

The content of GSS in the radial nerve cords (Figures 1A,B) has been shown to be equal in both sexes, when assayed with isolated ovarian fragments in vitro (20). GSS is also present in the radial nerve cords throughout the year and its quantity is mostly the same irrespective of the breeding season $(17,18)$.
In individuals, GSS mostly exists in the radial nerve cords and circumoral-nerve rings (20). However, GSS is also abundantly found in various other parts of the body, such as the epidermis, tube-feet and cardiac stomach, although its activity is much less than in the radial nerve cords (20). It is important that GSS is detected in the coelomic fluid only when individuals are undergoing natural spawning (20). Thus, this indicates that GSS is a hormone.

Microsurgical procedures show that GSS is located mostly in the supporting cells located under the cuticle layer of the surface of the radial nerve cords (Figure 1C) $(17,21)$. Histological studies also indicate that GSS is contained in neurosecretorylike granules in the same area of the radial nerve cords $(22,23)$. Further electron microscopic observations of the radial nerve cords and on GSS-containing granules isolated by differential centrifugation and sucrose density gradient ultracentrifugation from a homogenate of radial nerve cords show that GSS is present in granules contained in the supporting cells (21). Similar granules are also found in the subepithelial plexus of tube-feet, body wall, and cardiac stomach where GSS activity is detected $(20,23)$. Although the pyloric caecum contains an extensive nerve plexus, neither GSS granules nor GSS activity are detected. According to the histological study by Unger (24), GSS seems to be transported from the supporting cells along the supporting fibers in radial nerve cords to the radial and transverse haemal sinus (Figure 1C), and then to the water vascular system, thus reaching the coelomic cavity where the gonads are suspended.

\section{GONAD-STIMULATING SUBSTANCE}

Although GSS is the primary mediator of oocyte maturation and ovulation in starfish, the effect of GSS is indirect. The action of GSS is production of a second mediator, 1-MeAde, as an MIH in starfish (1-5). When GSS reaches the ovary, it enters the ovary and acts on follicle cells around oocytes to produce 1-MeAde $(25,26) .1$-MeAde is found from the incubation mixture of GSS and ovarian fragments of $A$. amurensis (1), and 1-MeAde induces spawning when injected into the coelomic cavity of ripe starfish (27). Isolated ovarian fragments also undergo spawning in seawater containing 1-MeAde. Thus, the GSS (gamete shedding substance) has been redesignated as gonad-stimulating substance (still termed GSS) (28).

The shedding of spermatozoa begins after a shorter latent period than that of eggs after 1-MeAde treatment. The intervals preceding the discharge of gametes after the injection of 1MeAde are almost equal to those found after injection of GSS. This indicates that 1-MeAde production in ovarian follicle cells begins immediately after GSS application (28-30).

Although GSS is thermostable, insoluble in organic solvents, and dialyzable, its activity is lost by treatment with proteolytic enzymes $(14,17,31)$, indicating that GSS is a peptide hormone. Chaet (32) first tried to purify GSS from radial nerve cords of Patiria miniata ( $P$. miniata). The result suggested that GSS consisted of at least 42 amino acid moieties, implying a minimum molecular weight of around 4,800. In contrast, the GSS purified from the radial nerve cords of $A$. amurensis showed that GSS 
A

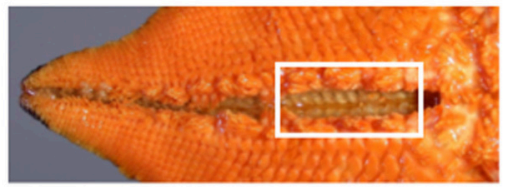

B

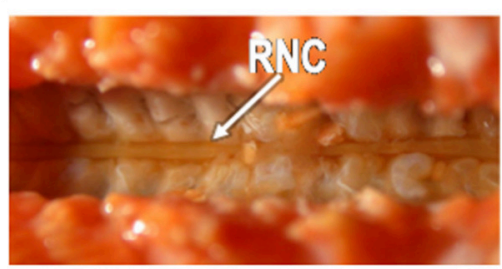

C

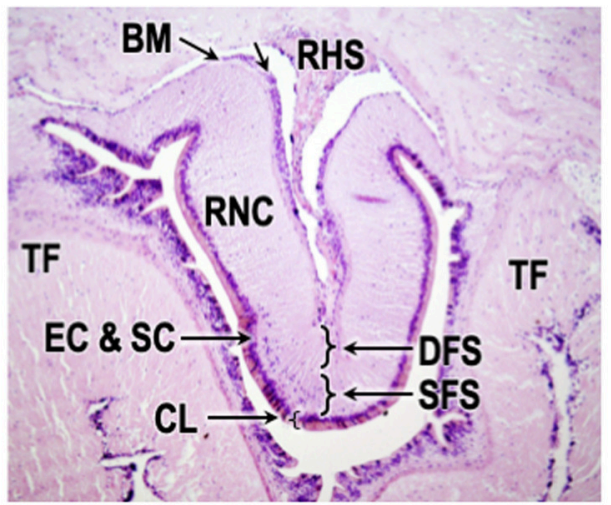

D

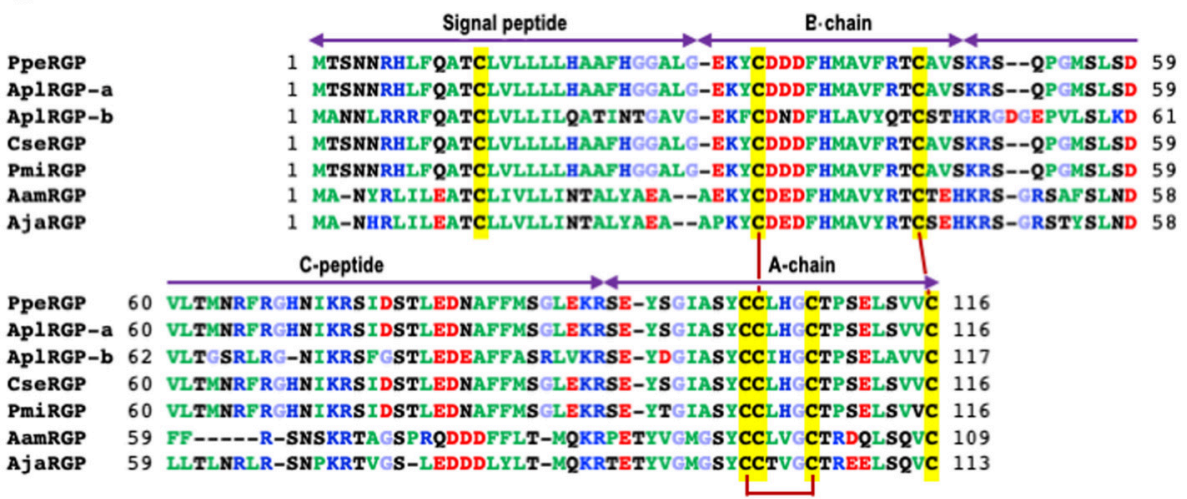

FIGURE 1 | Structure of radial nerve cords of starfish P. pectinifera and chemical structures of relaxin-like gonad-stimulating peptides (RGP) in various species of starfish. (A) Aboral surface of $P$. pectinifera. (B) Magnified image of the area in the square in (A). Arrow indicates radial nerve cords. (C) Cross-section of the tissue around radial nerve cord of $P$. pectinifera. The specimen was stained with hematoxylin-eosin. (D) Alignment of RGP pre-prohormone sequences of $P$. pectinifera, Acanthaster planci (A. planci), Certonardoa semiregularis (C. semiregularis), P. miniata, Asterisa amurensis (A. amurensis), and A. japonica. The signal peptide, C-peptide, B- and A-chains are indicated. To illustrate the conserved features, the amino acid types are color coded according to their nature with basic residues in blue (Arg, Lys, and His), acidic residues in red (Glu and Asp), hydrophobic residues in green (Ala, Val, lle, Phe, Trp, Tyr, Pro, and Met), hydrophilic in black (Ser, Thr, Asn, and Gln) and glycine in light blue. The cysteine residues are highlighted in yellow, and the disulfide bonds are shown by solid dark red lines. The abbreviations and the sequence sources [DDBJ accession numbers]: AamRGP, A. amurensis RGP (LC040882); AjaRGP, A. japonica RGP (LC104980); ApIRGP-a, A. planci RGP-a (LC033566); ApIRGP-b, A. planci RGP-b (19); BM, basement membrane; CL, cuticle layer; CseRGP, C. semiregularis RGP (LC066682); CT, connective tissue; DFC, deep fiber system; EC, epithelical cells; SC, sensory cells; PmiRGP, P. miniata RGP (LC057656); PpeRGP, P. (Asterina) pectinifera RGP (AB496611); RHS, radial heamal sinus; RNC, radial nerve cord; SFS, superficial fiber system; and TF, tube foot.

was a single peptide consisting of some 22 amino acids, with a molecular weight of about 2,100 (33). Since GSS is composed of two peptides combined by disulfide bonds (10), it might be possible that the disulfide bond of GSS is reduced during the purification process to become a single peptide. Despite active efforts, they could not determine the amino acid sequences of GSS, because the detection threshold of analytical instruments was insufficient at that time. It was also difficult to undertake physiological assays using chemically synthetic peptides.

\section{RELAXIN-LIKE GONAD-STIMULATING PEPTIDE}

It took 50 years since the initial finding by Chaet and McConnaughy (12) before GSS was finally purified from the radial nerve cords of starfish Patiria (synonym, Asterina) pectinifera and its chemical structure identified (10). For the purification of the GSS, $126.3 \mathrm{~g}$ wet weight of total radial nerve cords were collected from 5,500 animals (Figures 1A,B). The purification procedures are briefly described. After homogenization and extraction, the nerve extracts were applied to a four-step high-performance liquid chromatography (HPLC) procedure using a reverse-phase column. GSS activity was biologically assayed by ovarian fragments of $P$. pectinifera. After the 4th HPLC, GSS was finally purified and the amino acid sequence analyze using a protein sequencer and electronspray ionization-tandem quadruple/orthogonal-acceleration TOF MS/MS equipped with a nano-HPLC system. The purified hormone was a heterodimeric peptide with a molecular weight of 4,740 Da, comprising an A-chain of 24 amino acids (aa) and a B-chain of 19 aa, with disulfide cross-linkages; two 
interchain between the A- and B-chains, and an intrachain within the A-chain (10). The molecular weight of GSS in $P$. pectinifera was close to that of $P$. miniata estimated by Chaet (32). It is important that the A-chain contains a cysteine motif [CCxxxCxxxxxxxxC], which is a signature sequence of the insulin/insulin-like growth factor (IGF)/relaxin superfamily. Based on its cysteine motif, starfish GSS has been classified as a member of the insulin/IGF/relaxin superfamily. Furthermore, a
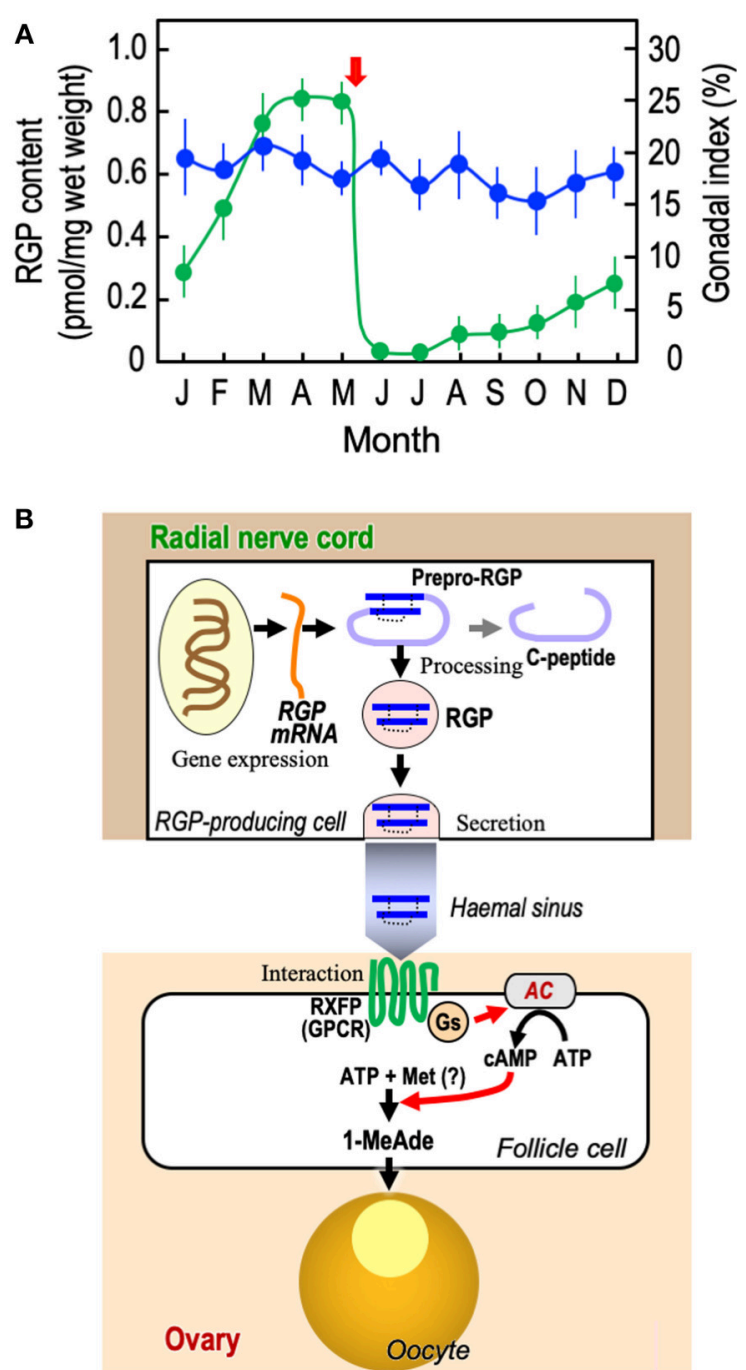

FIGURE 2 | Overview of RGP. (A) Annual changes in RGP content in radial nerve cords and gonadal index in starfish $P$. pectinifera. Starfish $P$. pectinifera were collected monthly from Yokosuka (Kanagawa Prefecture, Japan). More than ten individuals (arm length 30-50 mm) per group were used for measurement of gonadal index $(O$ and the preparation of radial nerve cord extracts for the measurement of RGP content ( ). RGP contents were determined by ELISA (40). The gonadal index was calculated as the gonad weight per body weight $\times 100$. Symbols and bars represent the mean of six independent samples and standard error of the mean (SEM), respectively. Arrow shows timing of spawning. (B) De novo synthesis, secretion, and hormonal action of RGP. AC, adenylyl cyclase; GPCR, G-protein-coupled receptor; Gs, G-protein as adenylyl cyclase stimulator; Met, methionine; and RXFP, relaxin-family peptide receptor. phylogenetic tree of the insulin/IGF/relaxin superfamily strongly suggests that GSS belongs to the relaxin-like peptide family (10). The name of GSS had not adequately expressed characteristics of a peptide hormone. Thus, GSS has been designated once again as a relaxin-like gonad-stimulating peptide (RGP) (34).

Synthetic RGP induces oocyte maturation and ovulation in ovarian fragments of $P$. pectinifera within $30 \mathrm{~min}$ of incubation. A median effective concentration is approximately $1-2 \mathrm{nM}$ (10). In contrast, neither oocyte maturation nor ovulation occurs when ovarian fragments are incubated with the A-chain alone, the B-chain alone, or a mixture of A- and B-chains. Additionally, spawning behavior and subsequent spawning can be seen after injection with synthetic RGP into the males and females of $P$. pectinifera with fully grown testes and ovaries, respectively (10).

The RGP gene in P. pectinifera (PpeRGP) consists of 3,896 base pairs (bp) comprising two exons and one intron. The lengths of exons 1 and 2 are 208 and 2,277 bp, respectively, with an intron of 1,411 bp between them (DDBJ: LC027939) (34). The transcript consists of 2,485 bases (b) in length (DDBJ: LC027938), although a size of the open reading frame (ORF) is $351 \mathrm{~b}$ (DDBJ: AB496611) (10). This indicates that only 14\% of the PpeRGP mRNA is translated into the peptide. Also, PpeRGP is a very highly conserved peptide, because genetic variation and polymorphism have not been found in the PpeRGP gene among ten local populations from Japanese waters (35). The ORF of PpeRGP encodes a peptide of 116 aa, including a signal peptide of 29 aa at the $\mathrm{N}$-terminus (10). The signal peptide is followed by the $\mathrm{B}$-chain, and the $\mathrm{A}$-chain is located at the $\mathrm{C}$-terminus. There is an intermediate sequence (C-peptide) of 44 aa between the Band A-chains, which have typical proteolytic cleavage sites, Lys and Arg, at the ends (Figure 1D). Thus, after the formation of three disulfide cross-linkages between the A- and B-chains and within the A-chain, mature RGP is produced by elimination of the signal and C-peptides.

The chemical structures of RGP in A. planci (AplRGP-a) (DDBJ: LC033566) (36), A. planci (AplRGP-b) (19), C. semiregularis (CseRGP) (DDBJ: LC066682) (35), and P. miniata (PmiRGP) (DDBJ: LC057656) (35) are almost the same as that of $P$. pectinifera (Figure 1D). Because A. planci, C. semiregularis, $P$. miniata, and $P$. pectinifera belong to the order Valvatida in the class Asteroidea, the chemical structure of PpeRGP is considered to be well-conserved among starfish of the order Valvatida beyond species (37).

In contrast, the chemical structures of RGP identified from A. amurensis (AamRGP) and A. japonica (AjaRGP) of the order Forcipulatida are quite different from that of PpeRGP $(38,39)$, although the cysteine motifs of AamRGP and AjaRGP coincide exactly with that of PpeRGP (Figure 1D). This suggests that AamRGP and AjaRGP are orthologs of PpeRGP. The molecular weights of AamRGP and AjaRGP are 5,156 and 5,117, respectively. The coding sequence (CDS) of AamRGP consists of 330 bp with an ORF encoding a peptide of 109 aa, including a signal peptide (26 aa), B-chain (20 aa), C-peptide (38 aa), and A-chain (25 aa) (Figure 1D) (DDBJ: LC040882) (38). The AjaRGP CDS is composed of 342 bp with an ORF encoding a peptide of 113 aa, comprising a signal peptide (26 aa), B-chain (20 
aa), C-peptide (42 aa), and A-chain (25 aa) (Figure 1D) (DDBJ: LC104980) (39). The identity levels of the CDS in AamRGP and AjaRGP with respect to PpeRGP were 68 and $67 \%$, although the homology between AamRGP and AjaRGP is $85 \%$. The amino acid sequences of AamRGP and AjaRGP are not quite the same as that of PpeRGP. This suggests that the chemical structure of AamRGP is close to AjaRGP rather than PpeRGP (37).

As already introduced, the GSS seems to be present in the radial nerve cords throughout the year and its quantity is mostly the same irrespective of the breeding season $(17,18)$. This was confirmed by enzyme-linked immunosorbent assay (ELISA) of PpeRGP using anti-PpeRGP antibody (40). The result showed that PpeRGP contents remained almost constant regardless of the breeding or non-breeding season, although the breeding season of $P$. pectinifera estimated by the gonadal index (GI) values was around May in Yokosuka (Kanagawa Prefecture, Japan) (Figure 2A). It is assumed that the amount of RGP secreted upon spawning is considerably lower than that stored in radial nerve cords. On the basis of in situ hybridization, the mRNA of RGP is detected in the peripheral area of radial nerve cords proximal to the tube-feet, but not at the side of the haemal sinus $(10,41)$. Thus, RGP is de novo synthesized in the radial nerve cords and circumoral-nerve rings which are functionally equivalent to the central nervous system in vertebrates.

In the breeding season, RGP secreted from the radial nerve cords should be transported to the gonads (Figure 2B). Because it has been shown that RGP is capable of being released from the radial nerve cords in the presence of ionomycin (42), an increase in the level of intracellular $\mathrm{Ca}^{2+}$ is closely associated with RGP secretion. In contrast, a gonadotropin-releasing hormonelike peptide, pEIHYKVPGWGPG- $\mathrm{NH}_{2}$ (DDBJ: LC131035), of $P$. pectinifera fails to induce RGP secretion in isolated radial nerve cords (37). The mechanism of RGP secretion from radial nerve cords is still unknown.

RGP binds specifically to a membrane preparation of ovarian follicles in starfish $(43,44)$, and the follicle cells cultured with RGP show a dose-related increase in cAMP production, coinciding with an increase in 1-MeAde production (10, 4446). The action of RGP is mediated through the activation of its receptor, leading to the activation of a G-protein and adenylyl cyclase in follicle cells (Figure 2B) $(10,46,47)$. In this sense, RGP is functionally identical to vertebrate $\mathrm{LH}$, especially piscine and amphibian LHs, acting on ovarian follicle cells to produce $\mathrm{MIH}$ to induce the final maturation or meiotic resumption of oocytes (48).

Previously, cross-species experiments using different species of starfish have shown that GSS generally acts non-species specifically, with some exceptions $(15,17,18)$. There are three kinds of RGP orthologs, PpeRGP, AamRGP, and AjaRGP, among the class Asteroidea (Figure 1D) (37). Neither AamRGP nor AjaRGP induces spawning in ovarian fragments of $P$. pectinifera $(38,39)$, although PpeRGP can induce spawning in $A$. amurensis and A. japonica ovaries (39). Presumably, partial speciesspecificity observed in AamRGP and AjaRGP is caused by interaction with the receptor. Thus, chimeric RGP derivatives with replaced A- and B-chain from these RGPs were synthesized and examined whether to induce spawning. The results suggest that the B-chain of RGP plays an important role in the interaction with the receptor (49).

Receptors for the relaxin family peptides (RXFPs) belong to the superfamily of rhodopsin-like G-protein-coupled receptors (GPCRs) $(50,51)$. In humans, the relaxin superfamily consists of relaxin 1 ( $\mathrm{H} 1$ relaxin), relaxin $2(\mathrm{H} 2$ relaxin), relaxin $3(\mathrm{H} 3$ relaxin), insulin-like peptide 3 (INSL3 also known as relaxinlike factor or Leydig insulin-like peptide), insulin-like peptide 4 (INSL4 or placetin), insulin-like peptide 5 (INSL5), and insulinlike peptide 6 (INSL6) (51-58). Previous studies have shown that $\mathrm{H} 2$ relaxin, INSL3, H3 relaxin, and INSL5 signal through RXFP1 (59), RXFP2 (60), RXFP3 (61), and RXFP4 (62) receptors, respectively. It is also considered that $\mathrm{H} 1$ relaxin is a ligand of the RXFP1 (63-65). However, the native receptors for INSL4 and INSL6 are yet to be identified (66). All the family members of relaxin peptides and their targets receptors have shown broad physiological roles (63-65). The activation of adenylyl cyclase by RXFP1 is complex and involves the interaction with several G-proteins, resulting in a biphasic pattern of cAMP accumulation (63). RXFP2 activates adenylyl cyclase in vitro but some physiological responses are sensitive to pertussis toxin (63). The signaling pathways activated by RXFP3 or RXFP4 result in the inhibition of adenylyl cyclase and a decrease in cAMP accumulation. Thus, it is possible that RGP receptor belongs to RXFP1/RXFP2 rather than RXFP3/ RXFP4, although the receptor has not been identified yet.

It has been demonstrated in mammals that the B-chain of relaxins and INSLs binds to the receptor (63-65). Despite its similarity with relaxin super family, however, the RGP sequence does not possess the vertebrate relaxin-specific receptor-binding cassette RxxxRxxI/V in the B-chain, a distinct and well-conserved feature of the relaxin group identified so far (67). A relaxin-like signaling system also exists in protostomes. Dilp8, Drosophila insulin-like peptide 8 , exerts role in developmental transitions via a signaling pathway involving the LGR3, a leucine-rich repeatcontaining G-protein coupled receptor, homologous to RXFP1 and RXFP2 (68). Because echinoderms belong to deuterostomes, starfish RGP and vertebrate relaxin are considered to be derived from the same ancestral peptide. Further studies on the receptor protein for RGP could provide useful insights into the hormonal action and evolution of species differentiation in the class Asteroidea.

\section{DATA AVAILABILITY}

All datasets generated for this study are included in the manuscript and/or the supplementary files.

\section{AUTHOR CONTRIBUTIONS}

MM conceived the study and wrote the paper.

\section{FUNDING}

This study was supported in part by JSPS KAKENHI Grant number JP16K07417. 


\section{ACKNOWLEDGMENTS}

Author is grateful to the late Professor H. Kanatani and Emeritus Professor Y. Nagahama (National Institute for Basic Biology);

\section{REFERENCES}

1. Kanatani $\mathrm{H}$, Shirai $\mathrm{H}$, Nakanishi $\mathrm{K}$, Kurokawa T. Isolation and identification of meiosis-inducing substance in starfish, Asterias amurensis. Nature. (1969) 221:273-4. doi: 10.1038/221273a0

2. Kanatani H. Maturation-inducing substance. Int Rev Cytol. (1973) 35:253-98. doi: 10.1016/S0074-7696(08)60356-3

3. Kanatani H. Hormones in echinoderm. In: Barington EJW, editor. Hormones and Evolution. Vol. 1. New York, NY: Academic Press (1979), p. 273-307.

4. Kanatani H, Nagahama Y. Echinodermata. In: Adiyodi KG. Adiyodi RG, editors. Reproductive Biology of Invertebrates. Vol. 1. Hoboken, NJ: John Wiley and Sons (1983), p. 611-54.

5. Kanatani H. Oocyte growth and maturation in starfish. In: Metz CB, Monroy A. editors. Biology of Fertilization. Vol. 1. New York, NY: Academic Press (1985), p. 119-40. doi: 10.1016/B978-0-12-492601-1.50012-1

6. Guerrier P, Moreau M, Dorée M. Hormonal control of meiosis in starfish: stimulation of protein phosphorylation induced by 1-methyladenine. Mol Cell Endocrinol. (1977) 7:137-50. doi: 10.1016/0303-7207(77)90063-6

7. Chiba K. Meiosis reinitiation in starfish oocyte. Zool Sci. (2000) 17:413-17. doi: $10.2108 /$ zsj.17.413

8. Kishimoto T. Entry into mitosis: a solution to the decades-long enigma of MPF. Chromosoma. (2015) 124:417-28. doi: 10.1007/s00412-015-0508-y

9. Mita M. Oogenesis, final oocyte maturation and ovulation, Echinoderms. In: Skinner MK. editor, Encyclopedia of Reproduction, Vol. 6. 2nd ed. Academic Press; Elsevier, (2018), p. 246-50. doi: 10.1016/B978-0-12-809633-8.20565-7

10. Mita M, Yoshikuni M, Ohno K, Shibata Y, Paul-Prasanth B, Pichayawasin $\mathrm{S}$, et al. A relaxin-like peptide purified from radial nerves induces oocyte maturation and ovulation in the starfish, Asterina pectinifera. Proc Nat Acad Sci USA. (2009) 106:9507-12. doi: 10.1073/pnas.0900243106

11. Roch GJ, Sherwood NM. Glycoprotein hormones and their receptors merged at the origin of metazoans. Genome Biol Evol. (2014) 6:1466-79. doi: $10.1093 /$ gbe/evu118

12. Chaet AB, McConnaughy RA. Physiologic activity of nerve extracts. Biol Bull. (1959) 117:407-8.

13. Chaet AB. A mechanism for obtaining mature gametes from starfish. Biol Bull. (1964) 126:8-13. doi: 10.2307/1539412

14. Kanatani H, Noumura T. On the nature of active principles responsible for gamete-shedding in the radial nerves of starfishes. J Fac Sci Univ Tokyo Sect IV. (1962) 9:104-14.

15. Noumura T, Kanatani H. Induction of spawning by radial nerve extracts in some starfishes. J Fac Sci Univ Tokyo Sect IV. (1962) 9:397-402.

16. Kanatani H. Spawning of starfish: action of gamete-shedding substance obtained from radial nerves. Science. (1964) 9:1177-9. doi: $10.1126 /$ science.146.3648.1177

17. Chaet $\mathrm{AB}$. The gamete-shedding substances of starfishes: a physiologicalbiochemical study. Am Zoologist. (1966) 6:263-71. doi: 10.1093/icb/6.2.263

18. Chaet AB. Neurochemical control of gamete release in starfish. Biol Bull. (1966) 130:43-58. doi: 10.2307/1539951

19. Smith MK, Wang T, Suwansa-Ard S, Motti CA, Elizur A, Zhao M, et al. The neuropeptidome of the Crown-of-Thorns Starfish, Acanthaster planci. J Proteom. (2017) 165: 61-8. doi: 10.1016/j.jprot.2017.05.026

20. Kanatani H, Ohguri M. Mechanism of starfish spawning I. Distribution of active substance responsible for maturation of oocytes and shedding of gametes. Biol Bull. (1966) 131:104-14. doi: 10.2307/1539651

21. de Angelis E, Viglia A, Watanabe T, Shirai H, Kubota J, Kanatani H. Presence of granules containing gonad-stimulating substance in starfish radial nerve. Annot Zool Jpn. (1972) 45:16-21.

22. Imlay MJ, Chaet AB. Microscopic observations of gametes shedding substance obtained from radial nerves. Trans Am Microsc Soc. (1967) 86:120-6. doi: $10.2307 / 3224677$
Professor M. R. Elphick (Queen Mary University of London); Professor D. Larhammar (Uppsala University); and Doctor H. Sakata (Suntory Foundation for Life Sciences) for their encouragement and valuable advice.

23. Atwood DG, Simon JL. Correlation of gamete shedding with presence of neurosecretory granules in Echinaster and Patiria (Echinodermata; Asteroidea). Am Zool. (1971) 11:701-2.

24. Unger H. Experimentelle und histologisch Untersuchungen über Wirkfactoren aus dem Nervensystem von Asterias (Marthasterias) glacialis (Asteroidea; Echinormata). Zool Jahrb Abt Allg Zool Physiol Tiere. (1962) 69:481-536.

25. Hirai S, Kanatani H. Site of production of meiosis-inducing substance in ovary of starfish. Exp Cell Res. (1971) 67:224-7. doi: 10.1016/0014-4827(71)90642-2

26. Hirai S, Chida K, Kanatani H. Role of follicle cells in maturation of starfish oocytes. Dev Growth Differ. (1973) 15:21-31. doi: 10.1111/j.1440-169X.1973.00021.x

27. Kanatani $H$. Induction of spawning and oocyte maturation by 1-methyladenine in starfishes. Exp Cell Res. (1969) 57:333-7. doi: 10.1016/0014-4827(69)90158-X

28. Kanatani H. Mechanism of starfish spawning: action of neuronal substance obtained ovary. Gen Comp Endocrinol Suppl. (1969) 2:582-9. doi: 10.1016/0016-6480(69)90068-9

29. Kanatani H, Shirai H. Mechanism of starfish spawning. III. Properties and action of meiosis-inducing substance produced in gonad under influence of gonad-stimulating substance. Dev Growth Differ. (1970) 12:119-40. doi: 10.1111/j.1440-169X.1970.00119.x

30. Mita M, Nakamura Y. Influence of gonad-stimulating substance on 1methyladenine level responsible for germinal vesicle breakdown and spawning in the starfish Asterina pectinifera. J Exp Zool. (1994) 269:140-5. doi: 10.1002/jez.1402690207

31. Schuetz AW. Chemical properties and physiological actions of a starfish radical nerve factor and ovarian factor. Gen Comp Endocrinol. (1969) 12:20921. doi: 10.1016/0016-6480(69)90193-2

32. Chaet A. Gamete released and shedding substance of sea-stars. In: Millot N. editor. Echinoderm Biology. Symp Zool Soc London. New York, NY: Academic Press. Vol 20. (1967):13-24.

33. Kanatani $H$, Ikegami S, Shirai $H$, Oide $H$, Tamura T. Purification of gonad-stimulating substance obtained from radial nerves of the starfish, Asterias amurensis. Dev Growth Differ. (1971) 13:151-64. doi: 10.1111/j.1440-169X.1971.00151.x

34. Haraguchi S, Ikeda N, Abe M, Tsutsui K, Mita, M. Nucleotide sequence and expression of relaxin-like gonad-stimulating peptide gene in starfish Asterine pectinifera. Gen Comp Endocrinol. (2016) 227:115-9. doi: 10.1016/j.ygcen.2015.06.017

35. Ikeda N, Uzawa H, Daiya M, Haraguchi S, Tsutsui K, Mita M. Relaxinlike gonad-stimulating peptide is highly conserved in starfish Asterina pectinifera. Invert Reprod Dev. (2015) 59:224-9. doi: 10.1080/07924259.2015 1091388

36. Mita M, Ikeda N, Haraguchi S, Tsutsui K, Nakano Y, Nakamura M. A gonadstimulating peptide of the crown-of-thorns starfish, Acanthaster planci. Invert Reprod Dev. (2015) 59:212-7. doi: 10.1080/07924259.2015.1086828

37. Mita M. Starfish gonadotropic hormone: relaxin-like gonadstimulating peptides. Gen Comp Endocrinol. (2016) 230-1:166-9. doi: 10.1016/j.ygcen.2016.04.016

38. Mita M, Daiya M, Haraguchi S, Tsutsui K, Nagahama Y. A new relaxin-like gonad-stimulating peptide identified in the starfish Asterias amurensis. Gen Comp Endocrinol. (2015) 222:144-9. doi: 10.1016/j.ygcen.2015.07.002

39. Mita M, Katayama H. A relaxin-like gonad-stimulating peptide from the starfish Aphelasterias japonica. Gen Comp Endocrinol. (2016) 229:56-61. doi: 10.1016/j.ygcen.2016.02.025

40. Mita M, Katayama H. Enzyme-linked immunosorbent assay of relaxinlike gonad-stimulating peptide in the starfish Patiria (Asterina) pectinifera. Gen Comp Endocrinol. (2018) 258:157-62. doi: 10.1016/j.ygcen.2017. 08.027 
41. Lin M, Mita M, Egertová M, Zampronio CG, Jones AM, Elphick MR. Cellular localization of relaxin-like gonad-stimulating peptide expression in Asterias rubens: new insights into hormonal control of spawning in starfish. J Comp Neurol. (2016) 525:1599-617. doi: 10.1002/cne.24141

42. Mita M. Release of relaxin-like gonad-stimulating substance from starfish radial nerves by ionomycin. Zool Sci. (2013) 30:602-6. doi: 10.2108/zsj.30.602

43. Mita M, Yamamoto K, Yoshikuni M, Ohno K, Nagahama Y. Preliminary study on the receptor of gonad-stimulating substance (GSS) as a gonadotropin of starfish. Gen Comp Endocrinol. (2007) 153:299-301. doi: 10.1016/j.ygcen.2007.01.038

44. Mita M, Yamamoto K, Nagahama Y. Interaction of relaxin-like gonadstimulating substance with ovarian follicle cells of the starfish, Asterina pectinifera. Zool Sci. (2011) 28:764-9. doi: 10.2108/zsj.28.764

45. Mita M, Ueta N, Nagahama Y. Regulatory functions of cyclic adenosine $3^{\prime}, 5^{\prime}$-monophosphate in 1-methyladenine production by starfish follicle cells. Biochem Biophys Res Commun. (1987) 147:8-12.

46. Mita M, Ueta $N$, Nagahama Y. Mediation of cyclic adenosine $3^{\prime}, 5^{\prime}$ monophosphate in 1-methyladenine production by starfish ovarian follicle cells. Gen Comp Endocrinol. (1989) 76:241-9.

47. Mita M, Nagahama Y. Involvement of G-proteins and adenylate cyclase in the action of gonad-stimulating substance on starfish ovarian follicle cells. Dev Biol. (1991) 144:262-8. doi: 10.1016/0012-1606(91)90420-8

48. Nagahama Y, Yoshikuni M, Yamashita M, Tokumoto T, Katsu Y. Regulation of oocyte growth and maturation in fish. Curr Top Dev Biol. (1995) 30:103-45. doi: 10.1016/S0070-2153(08)60565-7

49. Mita $M$, Nakamura $K$, Tsutsui $K$, Katayama $H$. Interaction of starfish gonadotropin with its receptor: effect of chimeric relaxin-like gonad-stimulating peptides. Gen Comp Endocrinol. (2019) 276:30-6. doi: 10.1016/j.ygcen.2019.02.019

50. Bathgate RA, Ivell R, Sanborn BM, Sherwood OD, Summers RJ. International Union of Pharmacology LVII: recommendations for the nomenclature of receptors for relaxin family peptides. Pharmacol Rev. (2006) 58:7-31. doi: $10.1124 /$ pr.58.1.9

51. Alexander SPH, Davenport AP, Kelly E, Marrio N, Peters JA, Benson $\mathrm{HE}$, et al. The concise guide to PHARMACOLOGY 2015/16: G proteincoupled receptors. Br J Pharmacol. (2015) 172:5744-861. doi: 10.1111/bph. 13348

52. Hudson P, Haley J, John M, Cronk M, Crawford R, Haralambidis J, et al. Structure of a genomic clone encoding biologically active human relaxin. Nature. (1983) 301:628-31. doi: 10.1038/301628a0

53. Crawford RJ, Hudson P, Shine J, Niall HD, Eddy RL, Shows TB. Two human relaxin genes are on chromosome 9. EMBO J. (1984) 3:2341-5. doi: 10.1002/j.1460-2075.1984.tb02136.x

54. Adham IM, Burkhardt E, Benahmed M, Engel W. Cloning of a cDNA for a novel insulin-like peptide of the testicular Leydig cells. J Biol Chem. (1993) 268:26668-72.

55. Chassin D, Laurent A, Janneau JL, Berger R, Bellet D. Cloning of a new member of the insulin gene superfamily (INSL4) expressed in human placenta. Genomics. (1995) 29:1414-21. doi: 10.1006/geno.1995.9980

56. Conklin D, Lofton-Day CE, Haldeman BA, Ching A, Whitmore TE, Lok $S$, et al. Identification of INSL5, a new member of the insulin superfamily. Genomics. (1999) 60:50-6. doi: 10.1006/geno.1999.5899
57. Chang GT, Steenbeek M, Schippers E, Blok LJ, van Weeerden WM, Alewijk DC, et al. Characterization of a zinc-finger protein and its association with apoptosis in prostate cancer cells. J Natl Cancer Inst. (2000) 92:1414-21. doi: 10.1093/jnci/92.17.1414

58. Bathgate RAD, Samuel CS, Burazin TCD, Layfield S, Claasz AA, Reytomas IGT, et al. Human relaxin gene $3(H 3)$ and the equivalent mouse relaxin (M3) gene. J Biol Chem. (2002) 277:1148-57. doi: 10.1074/jbc.M1078 82200

59. Hsu SY, Nakabayashi K, Nishi S, Kumagai J, Kudo M, Sherwood OD, et al. Activation of orphan receptors by the hormone relaxin. (2002) Science. 295:671-4. doi: 10.1126/science.1065654

60. Kumagai J, Hsu SY, Matsumi H, Roh JS, Fu P, Wade JD, et al. INSL3/Leydig insulin-like peptide activates the LGR8 receptor important in testis descent. J Biol Chem. (2002) 277:31283-6. doi: 10.1074/jbc.C2003 98200

61. Liu C, Chen J, Sutton S, Roland B, Kuei C, Farmer N, et al. Identification of relaxin-3/INSL7 as a ligand for GPCR142. J Biol Chem. (2003) 278:50765-70. doi: 10.1074/jbc.M308996200

62. Liu C, Kuei C, Sutton S, Chen J, Bonaventure P, Wu J, et al. INSL5 is a high affinity specific agonist for GPCR142 (GPR100). J Biol Chem. (2005) 280:292-300. doi: 10.1074/jbc.M409916200

63. Bathgate RAD, Halls M., van der Westhuizen ET, Callander GE, Kocan M, Summers RJ. Relaxin family peptides and their receptors. Physiol Rev. (2013) 93:405-80. doi: 10.1152/physrev.00001.2012

64. Patil NA, Rosengren KJ, Separovic F, Wade JD, Bathgate RAD, Hossain MA. Relaxin family peptides: structure-activity relationship studies. $\mathrm{Br} J$ Pharmacol. (2017) 174:950-61. doi: 10.1111/bph.13684

65. Bathgate RAD, Kocan M, Scott JD, Hossain MA, Good SV, Yegorov S, et al. Relaxin family peptides and their receptors. Pharmacol Ther. (2018) 187:114-32. doi: 10.1016/j.pharmthera.2018.02.008

66. Halls ML, van der Westhuizen ET, Bathgate RE, Summers RJ. Relaxin family peptide receptors-former orphans reunite with their parent ligands to activate multiple signaling pathways. Br J Pharmacol. (2007) 150:677-91. doi: 10.1038/sj.bjp.0707140

67. Büllesbach EE, Schwabe C. The relaxin receptor-binding site geometry suggests a novel gripping mode of interaction. J Biol Chem. (2000) 275:3527680. doi: 10.1074/jbc.M005728200

68. Jaszczak JS, Wolpe JB, Bhandari R, Jaszczak RG, Halme A. Growth coordination during Drosophila melanogaster imaginal disc regeneration is mediated by signaling through the relaxin receptor Lgr3 in the prothoracic gland. Genetics. (2016) 204:703-9. doi: 10.1534/genetics.116.193706

Conflict of Interest Statement: The author declares that the research was conducted in the absence of any commercial or financial relationships that could be construed as a potential conflict of interest.

Copyright (c) 2019 Mita. This is an open-access article distributed under the terms of the Creative Commons Attribution License (CC BY). The use, distribution or reproduction in other forums is permitted, provided the original author(s) and the copyright owner(s) are credited and that the original publication in this journal is cited, in accordance with accepted academic practice. No use, distribution or reproduction is permitted which does not comply with these terms. 